\title{
Programmed death-ligand 1 (PD-L1) expression in various tumor types
}

\author{
Joseph Grosso ${ }^{1 *}$, David Inzunza', Qiuyan Wu1, Jason Simon ${ }^{1}$, Parul Singh ${ }^{1}$, Xiaoling Zhang ${ }^{2}$, Therese Phillips ${ }^{2}$, \\ Pauline Simmons ${ }^{2}$, John Cogswell ${ }^{1}$ \\ From Society for Immunotherapy of Cancer 28th Annual Meeting \\ National Harbor, MD, USA. 8-10 November 2013
}

\section{Background}

Programmed cell death-1 (PD-1) is a co-inhibitory receptor expressed on lymphoid and non-lymphoidderived cells that negatively regulates peripheral $\mathrm{T}$-cell responses. PD-L1, the major PD-1 ligand, is expressed on various tumors and is being investigated as a possible predictive marker for anti-PD-1 therapy. Few studies have determined PD-L1 expression across tumor types using a consistent process. We evaluated PD-L1 expression across human tumor samples using a novel, automated, sensitive, and specific PD-L1 IHC assay (developed by Dako) using the $28-8$ antibody.

\section{Methods}

PD-L1 expression in 654 commercially available tumor samples was explored. Percentage of tumor plasma membrane staining was determined at $\geq 1+$ intensity. Macrophage and lymphocyte PD-L1 status was determined by compartment (tumor, non-tumor associated, or both). Immune cell density and PD-L1+ immune cell frequency were assessed on a scale of 0 (none), 1 (mild), 2 (moderate), and 3 (heavy). PD-L1 positivity was evaluated using $5 \%$ surface expression values for tumor cell membrane staining.

\section{Results}

Of 654 samples examined, spanning 19 tumors from different sites, 89 (14\%) were PD-L1+ ( $\geq 5 \%$ frequency). Highest PD-L1+ frequencies were seen in head and neck (17/54; 31\%), cervical $(10 / 34 ; 29 \%)$, cancer of unknown primary origin (CUP; 8/29; 28\%), glioblastoma multiforme (GBM; $5 / 20 ; 25 \%)$, bladder (8/37; 21\%), esophageal (16/ $80 ; 20 \%)$, triple negative (TN) breast $(6 / 33 ; 18 \%)$, and hepatocarcinoma $(6 / 41 ; 15 \%)$. Across a subset of head and neck tumor samples, high PD-L1 expression was seen: lip $(2 / 2 ; 100 \%)$, tongue $(2 / 4 ; 50 \%)$, larynx $(11 / 31$; $35 \%)$, and oral cavity $(2 / 10 ; 20 \%)$. In breast tumors, $\mathrm{TN}$ tumors showed a higher frequency PD-L1+ status $(\geq 5 \%$ frequency; $6 / 33$ samples [18\%]) compared with estrogen receptor, progesterone receptor, or HER2+ positive tumors $(0 / 45)$. PD-L1+ was higher in squamous (SQ) compared with other histologies within esophageal (SQ $[14 / 55 ; 25 \%]$ vs other $[2 / 25 ; 8 \%])$, cervical (SQ [6/15; $40 \%]$ vs adenoSQ $[2 / 8 ; 25 \%]$ and adeno $[0 / 5])$, and bladder (SQ [3/8; 37\%] vs transitional [6/27; 22\%]) tumors. PD-L1+ tumors were associated with immune cell density and PD-L1+ immune cells, especially in TN breast and laryngeal tumors.

\section{Conclusions}

PD-L1 is expressed in various human tumors and is associated with tumor grade, squamous histology, immune cell density, and co-localization of PD-L1+ immune cells. Highest PD-L1+ frequencies were seen in head and neck, cervical, CUP, GBM, bladder, esophageal, TN breast cancer, and hepatocarcinoma.

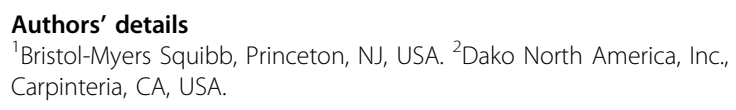

Published: 7 November 2013

doi:10.1186/2051-1426-1-S1-P53

Cite this article as: Grosso et al:: Programmed death-ligand 1 (PD-L1) expression in various tumor types. Journal for ImmunoTherapy of Cancer 2013 1(Suppl 1):P53.

'Bristol-Myers Squibb, Princeton, NJ, USA

Full list of author information is available at the end of the article

(c) 2013 Grosso et al; licensee BioMed Central Ltd. This is an Open Access article distributed under the terms of the Creative Commons Attribution License (http://creativecommons.org/licenses/by/2.0), which permits unrestricted use, distribution, and reproduction in any medium, provided the original work is properly cited. 